This item was submitted to Loughborough's Research Repository by the author.

Items in Figshare are protected by copyright, with all rights reserved, unless otherwise indicated.

\title{
An experimental investigation into bearing-induced spindle vibration
}

PLEASE CITE THE PUBLISHED VERSION

PUBLISHER

Professional Engineering Publishing / @ IMECHE

VERSION

VoR (Version of Record)

LICENCE

CC BY-NC-ND 4.0

\section{REPOSITORY RECORD}

Aini, R., Homer Rahnejat, and Ramsey Gohar. 2019. "An Experimental Investigation into Bearing-induced Spindle Vibration”. figshare. https://hdl.handle.net/2134/4818. 
This item was submitted to Loughborough's Institutional Repository (https://dspace.lboro.ac.uk/) by the author and is made available under the following Creative Commons Licence conditions.

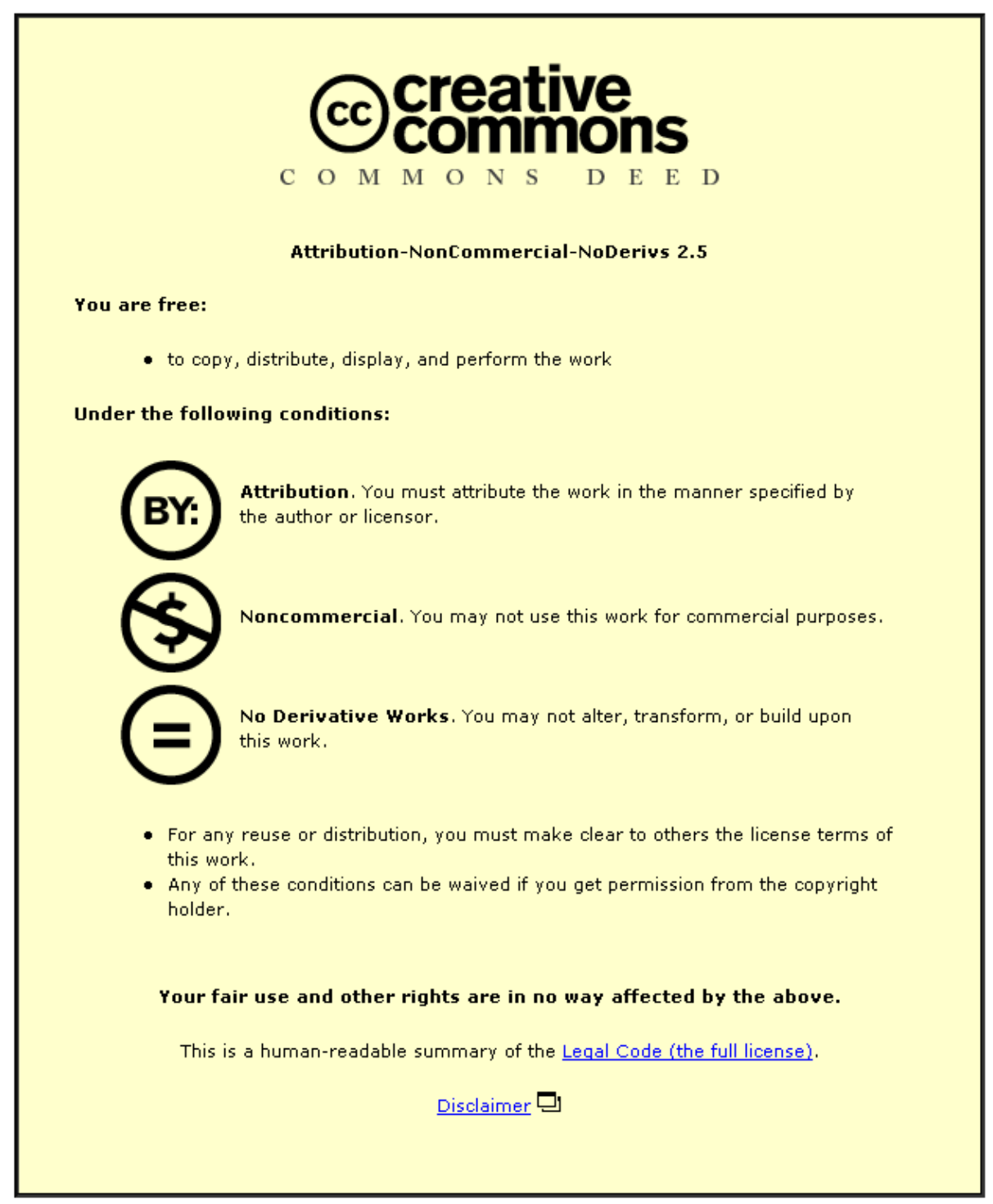

For the full text of this licence, please go to: http://creativecommons.org/licenses/by-nc-nd/2.5/ 


\title{
An experimental investigation into bearing-induced spindle vibration
}

\author{
R Aini, PhD \\ Department of Engineering Technology, Buckinghamshire College, A College of Brunel University, High Wycombe, \\ Buckinghamshire \\ H Rahnejat, BSc, MSc, PhD, DIC, CEng, MIMechE, FCybS \\ Department of Mechanical and Manufacturing Engineering, University of Bradford \\ R Gohar, BSc, MSc, PhD, DIC, CEng, MIMechE \\ Department of Mechanical Engineering, Imperial College of Science, Technology and Medicine, London
}

This paper describes experiments carried out to investigate the frequency response of a grinding machine tool spindle supported by preloaded angular-contact ball bearings. The experimental apparatus includes a loading device to simulate grinding head radial loads. The frequency spectra obtained show bands of frequencies associated with the ball passage frequency. The spectra also include bounce and rocking vibration modes of the assembly, where the supporting bearings act as non-linear springs.

Good correlation of the dominant frequencies was obtained with the results of the theoretical models published elsewhere.

Key words: machine tool spindle, static and dynamic stiffnesses, vibration behaviour, frequency response, angular-contact ball bearings

\section{NOTATION}

$A$ amplitude of $x$ oscillations

$b$ distance between the front (left) bearing and the centre of gravity of the spindle

$c$ distance between the rear (right) bearing and the centre of gravity of the spindle

$D$ ball diameter

$f_{1} \quad$ first-mode (bounce) frequency

$f_{2}$ second-mode (rock/pitch) frequency

$f_{\mathrm{b}}$ ball passage frequency

$f_{s}$ shaft frequency

$K \quad$ linearized bearing stiffness

$K_{1} \quad$ linearized front bearing stiffness

$K_{2}$ linearized rear bearing stiffness

$m$ mass of the spindle assembly

$n$ number of balls in each bearing

$r_{i} \quad$ inner race radius

$t$ time

$x$ transverse radial vertical direction

$y$ transverse radial horizontal direction

$z \quad$ axial direction of the spindle

$\alpha_{p} \quad$ preloaded contact angle

$\boldsymbol{\theta}$ pitch/rock oscillations

$\varphi$ amplitude of pitch/rock oscillations

$\omega_{1}$ first-mode (bounce) radiancy

$\omega_{2}$ second-mode (rock/pitch) radiancy

$\omega_{c}$ cage set angular speed

$\omega_{\mathrm{s}}$ shaft angular speed

\section{INTRODUCTION}

The quality of a manufactured product is often no better than the quality of the machine tool that pro-

The MS was received on 15 July 1994 and was accepted for publication on 20 October 1994.

C06094 @ IMechE 1995 duces it. In this paper the effect of vibration on the accuracy of a machine tool spindle is investigated.

There are a number of factors that influence the performance of machine tool spindles, such as manufacturing defects of the rolling contacting members and errors incurred in assembly of parts. Another important factor is to make the correct choice of bearings for the shaft. Some of the above factors determine the static and dynamic stiffnesses of the machine tool spindle and its vibration behaviour, which can be critical design parameters.

Static stiffness, which depends on the rigidity of all machine tool components (mountings, bearings, etc.), is a measure of the flexibility between the workpiece and the tool. For dynamic stiffness, an optimum bearing stiffness and a minimum bearing spacing is required (1, 2). Dynamic flexibility at the cutting point of a machine tool spindle is desired in order to reduce its susceptibility to vibrations and chatter $(\mathbf{1}, 2)$.

The success of the above general design criteria in a given case is usually ascertained through prototyping and noise and vibration monitoring. Noise and vibrations can then be attributed to design shortcomings, which can be related to incorrect choices having been made in the selection of bearings, shaft design, methods of assembly, preloading, etc. (3). This is the approach outlined in this investigation.

The method used for the simulation and the results for a particular case of a precision grinding spindle appear elsewhere $(4,5)$. In this paper an outline of the experimental vibration monitoring results on the same grinding spindle is presented. The advantages gained by using the above mentioned approach are highlighted and the use of some simulation results gives a better understanding of the complex experimental vibrations spectra found.

The simulation method employed was first reported 
by Rahnejat and Gohar (6) for a two degree of freedom investigation of a rigid rotor supported by a pair of deep groove ball bearings. The model was re-examined and expanded by Aini (3-5) to incorporate the use of angular-contact ball bearings in cases where combined axial and radial loads were applied. In its latest form, the simulation model investigates five degree of freedom vibrations of a rigid shaft supported by a pair of backto-back angular-contact ball bearings. The model incorporates such effects as asymmetric loading of the spindle, resulting in the application of gyroscopic forces and conical whirling of the spindle (3). Readers are referred to references (3) to (5) for a full description of the simulation method employed.

Recent advances in sensor and instrumentation technologies have enabled fast Fourier transform (FFT) algorithms to be used for the acquisition and analysis of experimental vibration signals in real time. Highfrequency vibration levels are usually modulated with the fundamental shaft frequency or with characteristic frequencies of machine elements as shown by Harting (7). In general, however, average high-frequency vibration levels and modulated effects are of low amplitude except for localized defects such as defective balls or faulty raceway tracks. Therefore, the most significant frequencies to watch for in a design evaluation exercise are those associated with variable compliance vibrations $(6,8)$ which are present as a result of the orbiting rolling elements complement. The modulation of such inherent sources of vibrations with the shaft frequency is an important design consideration, especially for precision rotors/spindles operating at low to moderate speeds where the first rigid mode of the rotor is to be avoided. At higher speeds multiples of the ball passage frequency can also modulate with the rotor flexure modes and limit the operational speed of the rotors. Therefore, in a coherent design and test exercise the aim is to investigate the rotor/bearings rigid-body resonant frequencies, the bearings variable compliance vibration frequency, the shaft frequency and their modulation effects together. For this purpose an experimental rig using a non-contact vibration sensor was employed.

\section{TEST RIG DESIGN AND DESCRIPTION}

Figure 1a shows the experimental arrangement. The grinding spindle has a small $L / D$ ratio. The reason for this is to increase the response frequencies related to shaft flexure modes, thereby reducing the chance of resonance in the normal operational speed range of $1000-5000 \mathrm{r} / \mathrm{min}$. The shaft is mounted on a pair of super finish, high-performance, angular-contact ball bearings (RHP $7008,15^{\circ}$ unloaded contact angle) in a back-to-back arrangement. The bearings are slide and interference fitted into the housing and on to the shaft. Hence a nearly clearance-free radial fit is ensured.

A solid cylindrical housing is used which ensures accurate alignment of the shaft and bearings. The housing is force fitted into a heavy rectangular mounting which in turn is fixed to a heavy solid base to stiffen further the spindle (see Fig. 1b). An externally threaded lock-nut is screwed to the housing to provide an abutment to the front-end bearing.

Spring preloading is incorporated into the system to achieve thermal stability and maintain high dynamic stiffness. The spring preloading system consists of 12 equally spaced, equally stiff springs together with their supporting ring with a minimum load capacity of $100 \mathrm{~N}$. The internally threaded lock-nut (see Fig. 1a), screwed on to the shaft, ensures the final adjustment/ alignment of the rear bearing.

The spindle is directly coupled to a $3 \mathrm{HP}$ electric motor via an all-metal flexible coupling. This is a triplelaid spring assembly device which transmits high torques with a constant torsional flexibility, thus effectively isolating the spindle from motor vibrations. The motor and the spindle are mounted on separate heavy bases and vibration isolating pads are laid under the massive base of the electric motor, as well as the spindle, in order to isolate the spindle mounting from floor-transmitted motor vibrations. Sandbags are also placed on the spindle base mount, which is bolted to the ground to further ensure its rigidity.

A compressed air/oil mist supply flows through machined channels into the mounting and housing and supplies the necessary lubrication for the bearings.

A loading device was designed to exert the required radial forces to the spindle assembly (see Fig. 1c). Its loading mechanism simulates the force generated in the grinding process. It consists of a steel ball of $25.4 \mathrm{~mm}$ diameter which resides in a hollow cylindrical block of $25.45 \mathrm{~mm}$ bore loaded pneumatically against the spindle tip. The incoming air passes through a pressure regulator, thus enabling load variation.

\section{THE VIBRATION MONITORING TRANSDUCER}

An eddy current sensor is employed to measure directly the small amplitude vibrations at the spindle nose. The sensor is mounted in a holder, supported by a long cantilever arm which is attached to a remote sidewall away from the spindle and motor mountings. This ensures sensor isolation from rig vibrations. Vibration isolating pads are also placed at various positions between the lever support and the wall as well as the lever and the sensor holder. The sensor is positioned $110 \mu \mathrm{m}$ above the spindle nose (see Fig. 1c). The latter was lapped to a super finish using a copper alloy jig greased with diamond paste which gently rubbed the spindle surface in a random manner. The sensor has a monitoring resolution of $40 \mathrm{mV}$ per $1 \mu \mathrm{m}$ displacement of the spindle. The d.c. voltage is removed from the incoming signal via a purpose-built circuit board. The signal is further processed by a band-pass filter in order to remove the signal noise content by setting the filter to pass signals above $15 \mathrm{~Hz}$ and below $5 \mathrm{kHz}$.

$1 \mathrm{~K}$ (1024) samples are acquired in a given time window by the $B \& K$ frequency analyser through the sensor. The spectrum contains all sources of synchronous (that is one-off character) and asynchronous vibrations. Synchronous signatures are filtered out by a process of spectral storage and averaging. The remaining asynchronous vibrations are attributed to the spindle/bearings. The number of spectra used continuously by this process is 64 .

\section{RESULTS AND DISCUSSION}

To study the vibration characteristics of the grinding spindle the natural modes of the assembly need to be 
1 Loading device

2 Externally threaded lock-nut

3 Lubrication nozzles

4 Spring preloading unit

5 Solid cylindrical housing

6 Internally threaded lock-nut

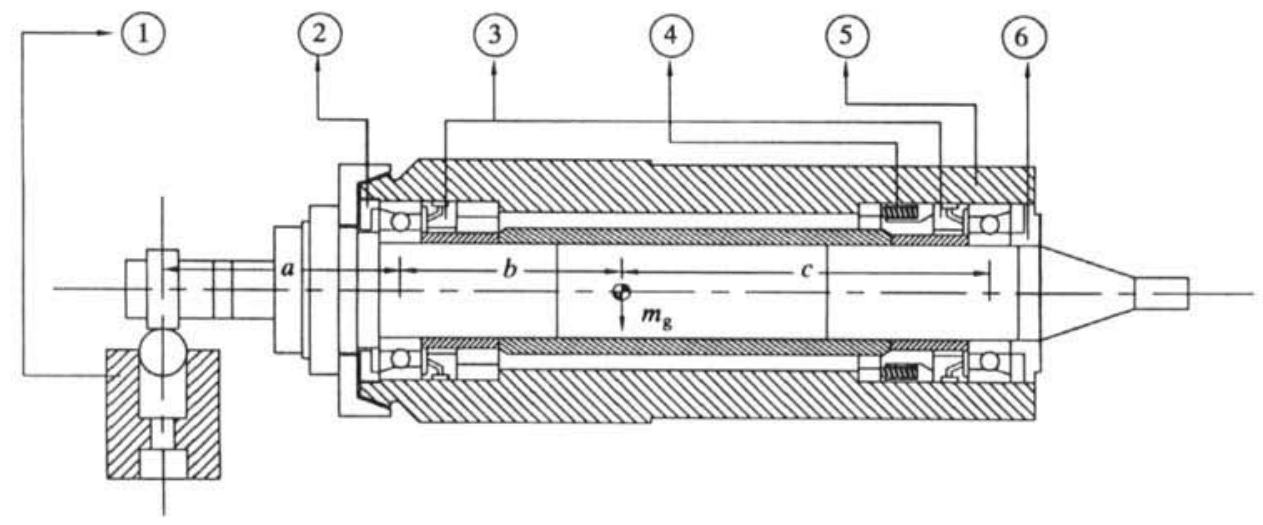

(a) The experimental arrangement

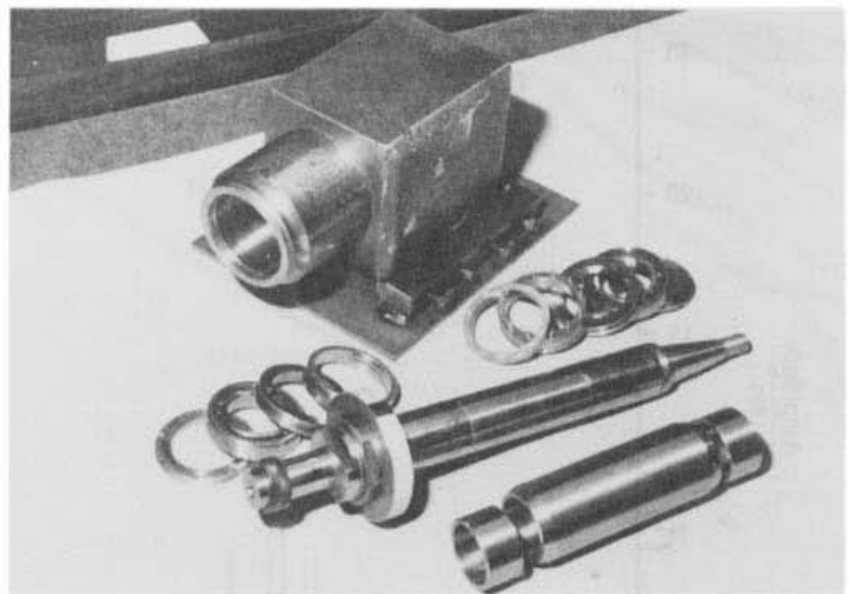

(b) The housing and mounting arrangement

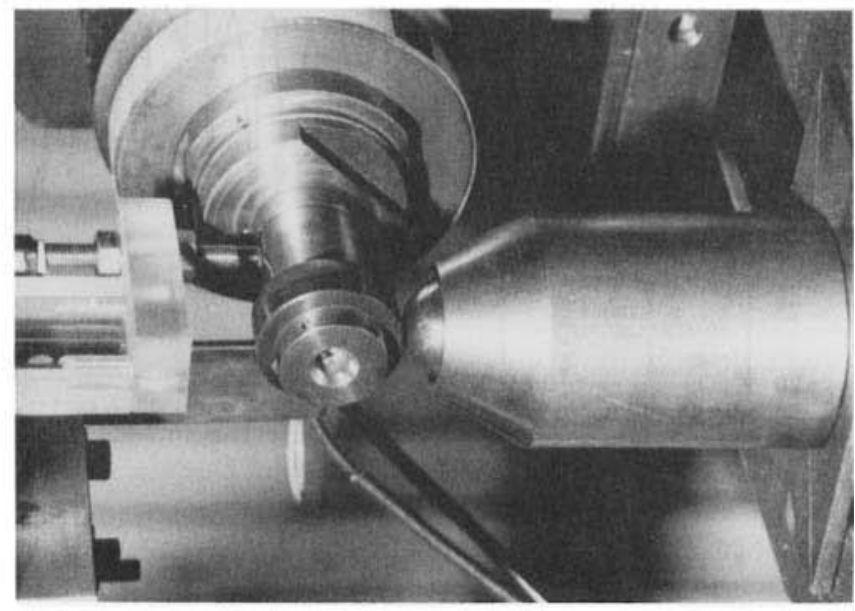

(c) The loading device arrangement

Fig. 1 The precision grinding spindle

established. In the case of a bearing, obtaining its natural modes is rather complex. This is due to the number of factors that influence these phenomena such as the type of bearing, the number of rolling elements in a bearing set, the method of preloading, etc. However, the natural modes of the bearings/spindle assembly as a whole can be determined through impact (hammer) testing.

Impact (hammer) testing of the static spindle assembly was conducted normal to its longitudinal axis at the point of application of the external applied force. The spindle response was registered using a piezoelectric accelerometer and the non-contacting eddy current sensor. Figure $2 a$ and $b$ illustrates the resulting spindle frequency spectrum obtained. Three bands of frequencies have been specified that fall within the operating speed range of the spindle. As shown in Fig. 2, the dotted lines indicate the positions of the principal modes as predicted by a simulation model (3-5). The fundamental bounce mode in the vertical transverse plane is noted in the $0.7-1.2 \mathrm{kHz}$ region. The band of frequencies associated with the axial vibrations is observed in the $0.0-0.7 \mathrm{kHz}$ region, with two dominant peaks at 230 and $570 \mathrm{~Hz}$. A third frequency band, appearing between 1.2 and $2.0 \mathrm{kHz}$, corresponds to the rock/pitch mode of the spindle assembly. The band of frequencies at $2.75-3.95 \mathrm{kHz}$ (Fig. 2a) corresponds to the flexural modal responses of the shaft. The justification for this observation is discussed below.

Under dynamic conditions, the dominant frequencies are due to the contribution of the shaft rotational speed and its higher harmonics as well as the ball passage frequencies. The vibration spectrum also includes peaks which are probably due to such effects as off-centre rotation, out of roundness, waviness and distributed roughnesses. Wardle (9) analysed the response characteristics of a precision angular-contact ball bearing in isolation from its distributed manufacturing defects (that is wavy inner/outer raceways and the balls). Experimental study of the same bearing revealed close

Proc Instn Mech Engrs Vol 209 


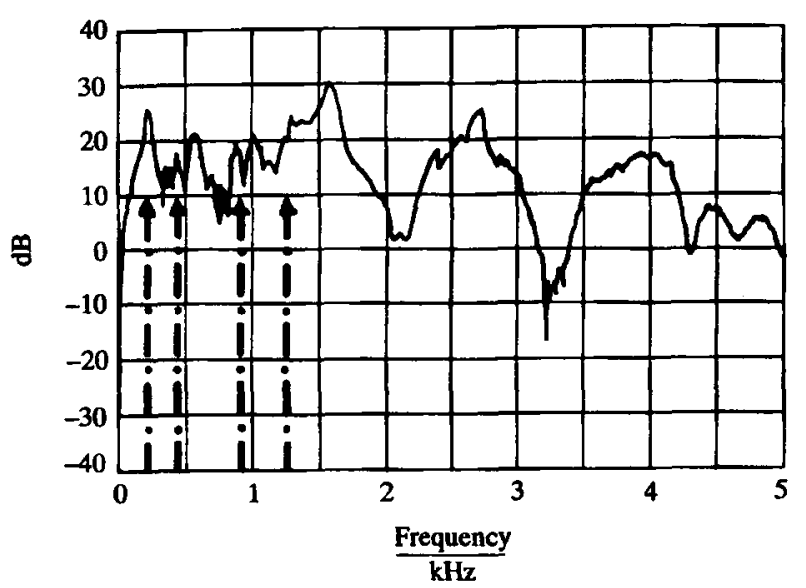

(a)

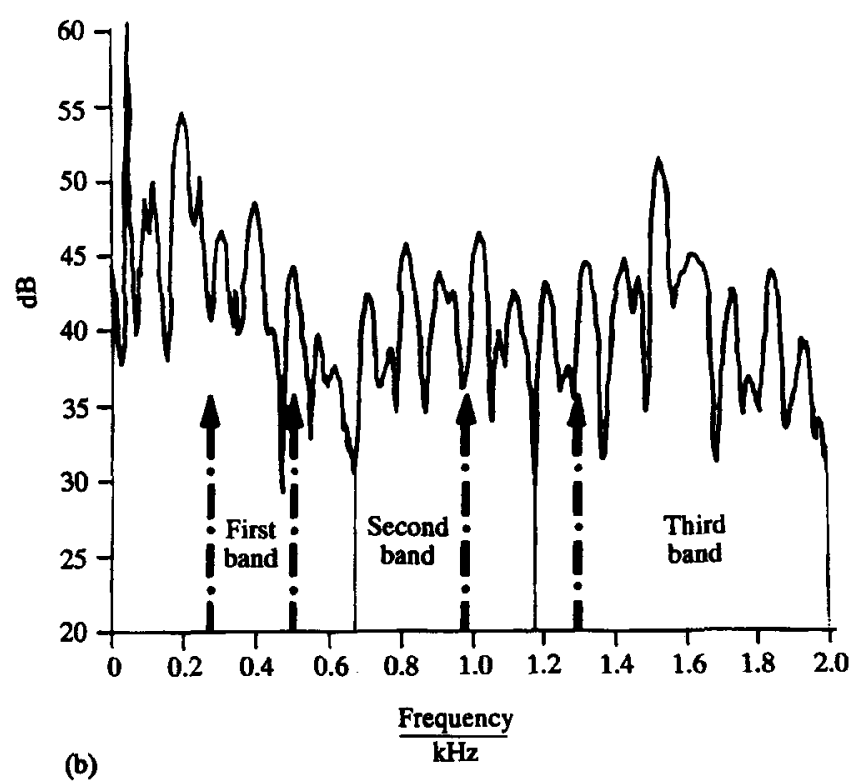

Fig. 2 Frequency spectra obtained using (a) an accelerometer and (b) an eddy current proximity sensor

correlation between the analytical and experimental results (10), which showed that the first $1 \mathrm{kHz}$ of the vibration spectrum is covered with frequencies associated with the ball passage, wave, inner race relative to the ball and the balls relative to the outer raceway.

In the case of the grinding spindle used here, the complexity of the vibration spectrum is twofold because of the location of support bearings in relation to the externally applied force and the fact that no two bearings are identical in terms of their manufactured surface defects. Furthermore, it would be quite difficult, if not impossible, to isolate and identify these peaks, even by matching the response to their simulated counterparts, as the latter is usually obtained for an ordered mathematical function. The modulation of these sources of vibrations with fundamental frequencies of the system make their identification an even harder task. However, when hydrostatically loaded vertical rotors are modelled or experimentally monitored, less complex spectra result and bearing vibrations can be isolated and identified more readily, as shown by Wardle (9) and Meyer et al. (11).

Figure $3 a$ and $b$ shows the frequency spectra obtained under a constant spindle speed of $1000 \mathrm{r} / \mathrm{min}$.
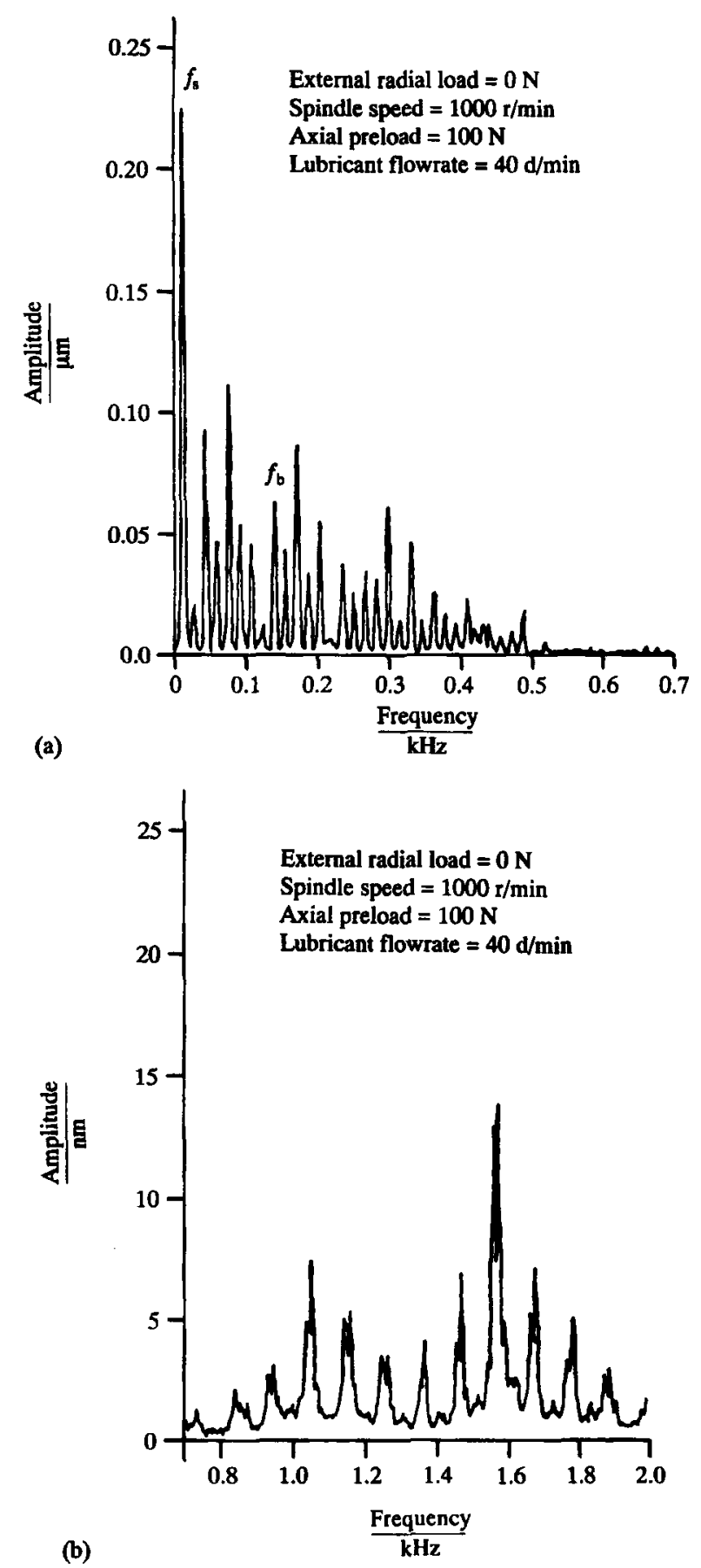

Fig. 3 Experimental frequency spectra at a constant spindle speed of $1000 \mathrm{r} / \mathrm{min}$

The shaft frequency at $16.6 \mathrm{~Hz}$ with an amplitude of $0.225 \mu \mathrm{m}$ is the dominant peak in the spectrum. The ball passage frequency is at $151 \mathrm{~Hz}$, the first fundamental (bounce mode) is at $1050 \mathrm{~Hz}$ and the third frequency due to the spindle rocking/pitching mode appears around $1590 \mathrm{~Hz}$. The numerical value of these modes have been confirmed by using a detailed mathematical model $(3-5)$ that incorporates the non-linear characteristics of the support bearings. A simplified verification of the model is presented in the Appendix for a pair of linear (constant stiffness) bearings.

As the spindle speed is increased to $4800 \mathrm{r} / \mathrm{min}$, the amplitude at the shaft frequency has increased to 1.125 $\mu \mathrm{m}$, probably owing to unavoidable out-of-balance (see 

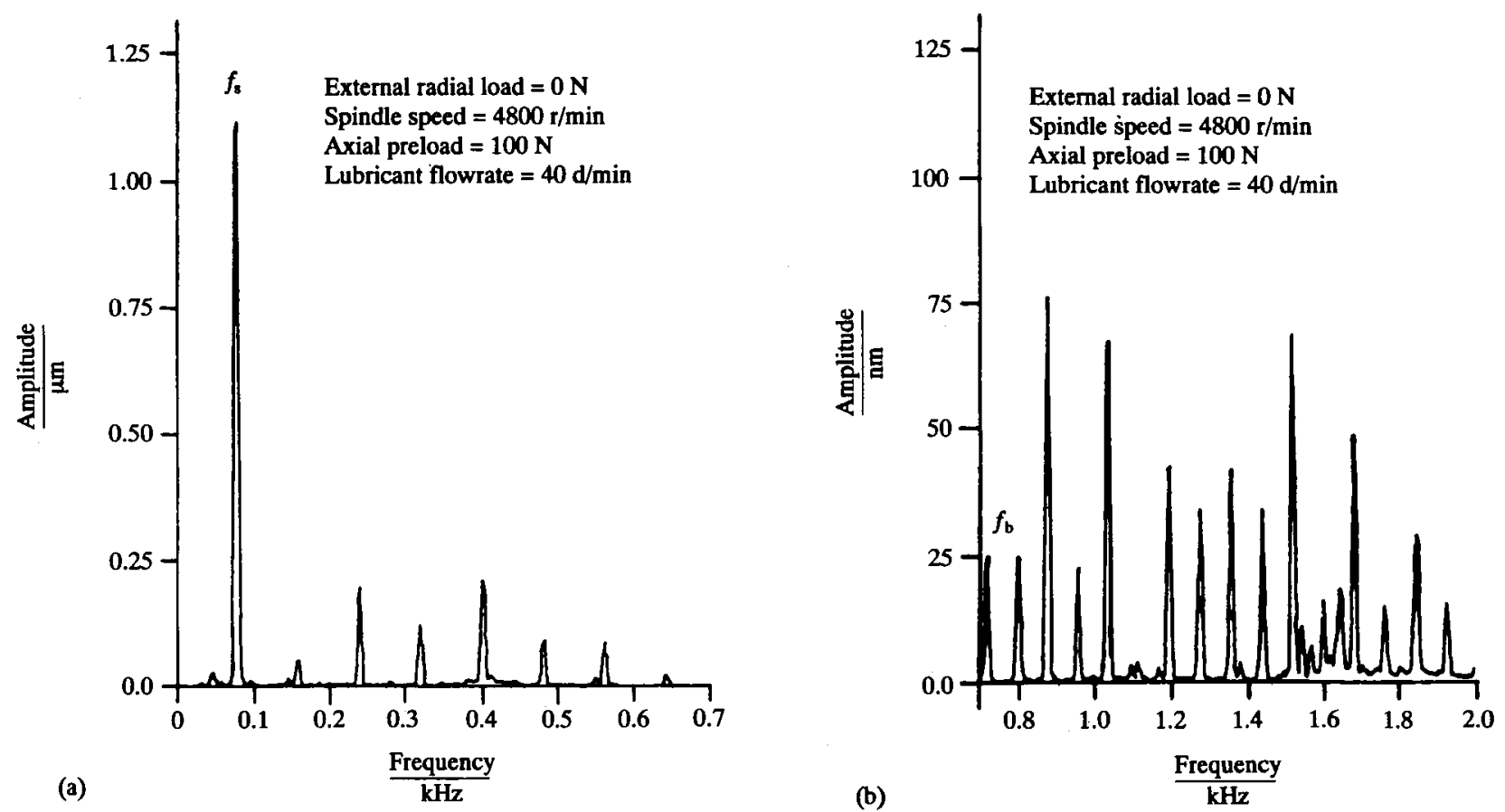

Fig. 4 Experimental frequency spectra at an increased spindle speed of 4800 $\mathrm{r} / \mathrm{min}$

Fig. 4a and b). The amplitude at the rock/pitch mode (that is $1590 \mathrm{~Hz}$ ) experienced a fivefold rise even though the shaft frequency and its higher harmonics operate well below this frequency. There is also an order of magnitude rise in the amplitude at the first fundamental bounce frequency from 7.5 to $75 \mathrm{~nm}$. This is attributed to the intrusion of the ball passage frequency into this region, causing a modulation effect to take place.

Depending on the shaft rotational speed and the number of rolling elements in a bearing complement, the ball passage frequency appears around a frequency of 6-7 times the value of the shaft frequency, since 'the ball passage frequency' $=n\left(\omega_{\mathrm{s}}-\omega_{\mathrm{c}}\right)$, where

$$
\omega_{c}=\frac{\omega_{s} r_{i}}{2\left(r_{i}+D \cos \alpha_{p} / 2\right)}
$$

$\omega_{\mathrm{s}}$ is the shaft speed, $\omega_{\mathrm{c}}$ is the cage speed, $n$ is the number of balls, $D$ is the ball diameter, $r_{\mathrm{i}}$ is the inner race radius and $\alpha_{p}$ is the preloaded contact angle (3).

In order to cause resonance by virtue of the increasing shaft speed, a speed of $65000 \mathrm{r} / \mathrm{min}$ would be required. This would cause the shaft frequency to coincide with the first fundamental bounce frequency at $1050 \mathrm{~Hz}$. However, a premature resonance could occur at $9000 \mathrm{r} / \mathrm{min}$ due to the ball passage frequency coinciding with the first fundamental (that is bounce) mode.

The grinding spindle employed is usually used for final surface finishing operations. It is normally subjected to a fixed radial force of 5-35 $\mathrm{N}$ and a small superimposed dynamic component of one-twentieth to one-tenth of the fixed radial force. The small variations in dynamic forces about a fixed constant force in precision grinding operations is shown by Hahn (12). In order to investigate the effect of applied radial forces, the spindle tip was loaded using the loading device described in Section 2.

With the spindle speed kept constant, a steady exter- nal load was exerted on the spindle tip. With no applied external forces and a spindle speed of $3000 \mathrm{r} / \mathrm{min}$ the amplitude of vibrations at the shaft and ball passage frequencies were recorded as 0.8 and $0.0875 \mu \mathrm{m}$ respectively (see Fig. 5a).

Figure $5 b$ and $c$ shows that when the magnitude of the external force was increased to $32 \mathrm{~N}$, the amplitude associated with the shaft frequency reaches a maximum value of $1.45 \mu \mathrm{m}$. The amplitude of vibration at the ball passage frequency, on the other hand, was reduced from 87.5 to $75 \mathrm{~nm}$ due to the reduced load intensity in the loaded regions of ball/races contacts (in particular in the front bearing). Furthermore, due to the application of this external radial load the band of frequencies associated with the bounce mode was packed together and moved towards the stiffer regions of the vibrations spectrum with a maximum amplitude of $50 \mathrm{~nm}$. This is shown in Fig. $5 \mathrm{c}$ where the ratio of the applied external force to axial preload $\left(F / P_{r}\right)$ is 0.32 .

Figure 6 is taken from the results of references (3) and (4). It shows the simulated effect of the external radial force to axial preload as a ratio of the amplitude of oscillations in the radial $x$ direction and the corresponding axial $z$ oscillations. For the $F / P_{\mathrm{r}}$ ratio of 0.32 the amplitude of vibrations in the $x$ direction is approximately $50 \mathrm{~nm}$ (as shown in Fig. 6), indicating that the experimental findings are corroborated by the results of the simulation model of references (3) and (4). Figure $5 \mathrm{c}$ also shows that the position of rocking and pitching modes are largely unchanged as asymmetrical loading restricts oscillations about the $x$ and $y$ axes (see Fig. 1a). Increasing the magnitude of the applied radial force changes the initial stiffness of the system, determined by the axial preload and radial interference fit. At higher speeds and with larger applied forces, gyroscopic effects could become significant and conical whirling of the spindle tip can take place. 


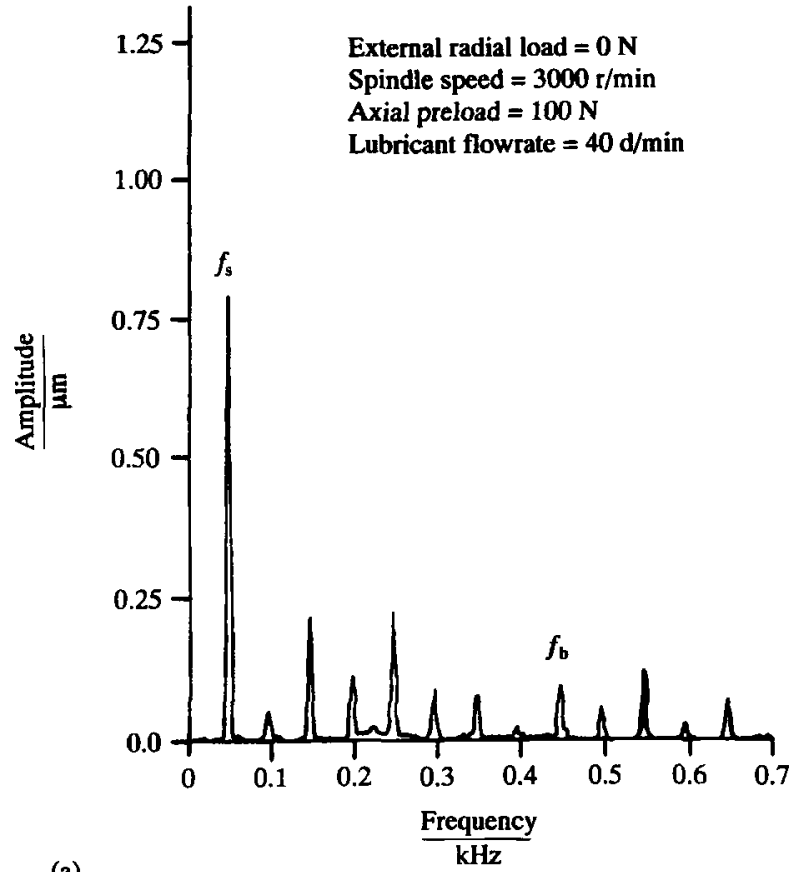

(a)

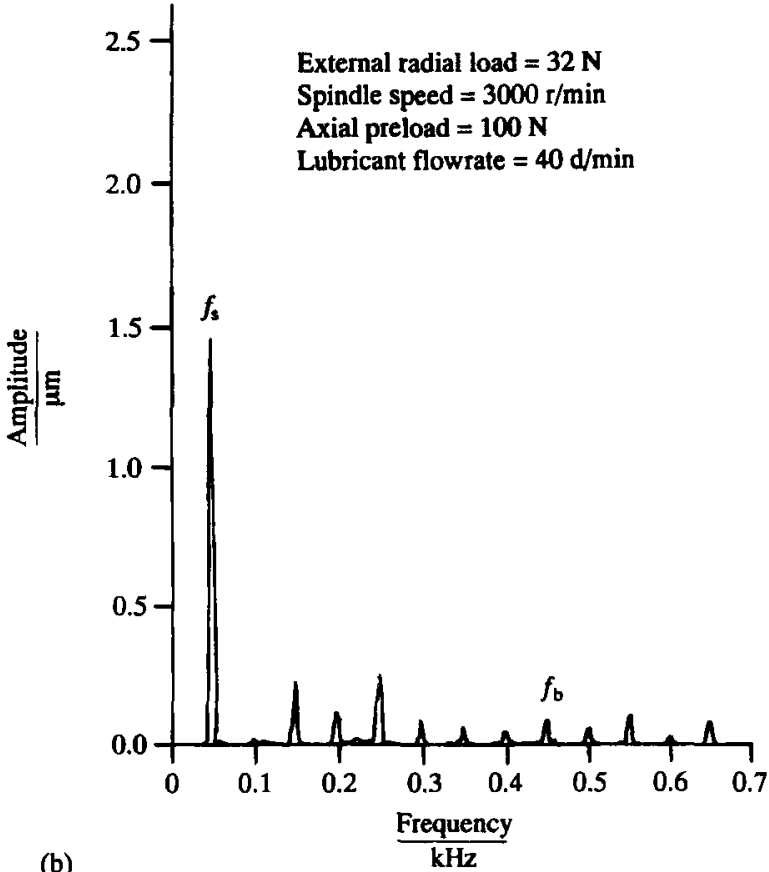

(b)

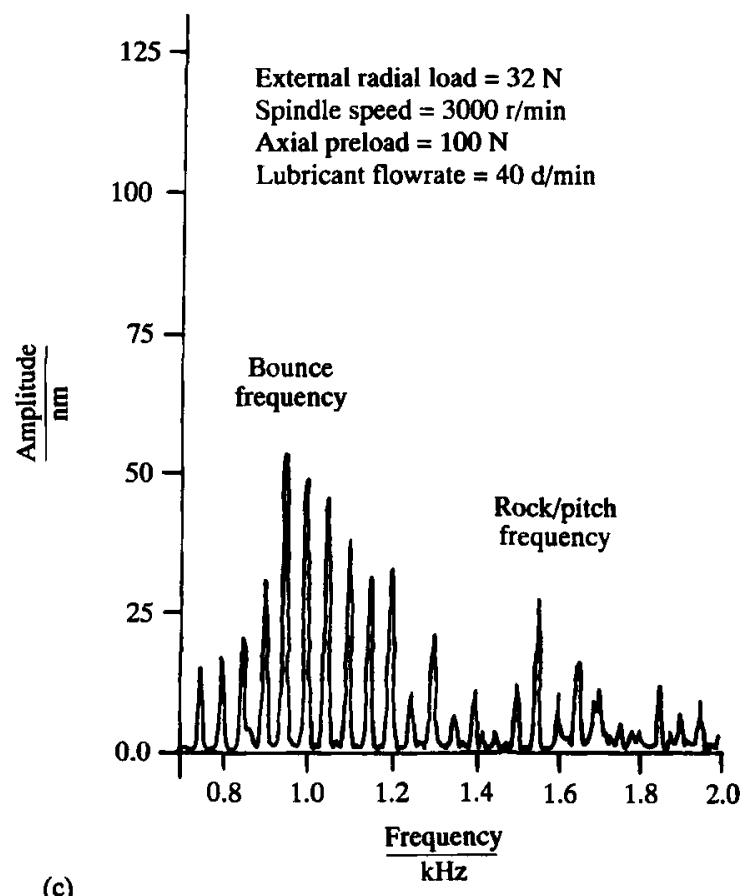

Fig. 5 Experimental frequency spectra at a spindle speed of $3000 \mathrm{r} / \mathrm{min}$ and increasing external force

Figure $7 a$ and $b$ presents the final comparison made between the result of an experimental spectrum with an axial preload of $100 \mathrm{~N}$ and spindle speed of $1000 \mathrm{r} / \mathrm{min}$ with its simulated counterpart (shown as dotted lines). Figure $7 \mathrm{~b}$ shows that the position of the dominant frequencies match quite closely.

\section{CONCLUSION}

An experimental investigation into the vibrational characteristics of a precision grinding spindle was per- formed. A number of peaks appeared in the frequency spectrum of the spindle which are attributed to the support characteristics of the bearings.

Modulation of these frequencies with the rigid-body resonant modes of the spindle adversely affect its dynamic performance. This interaction cannot be readily understood. However, identification of the major modes from the cluster of peaks obtained experimentally was made possible by simulating the operating condition of the spindle and comparing the results with their experimentally obtained counterpart. Close correlation 


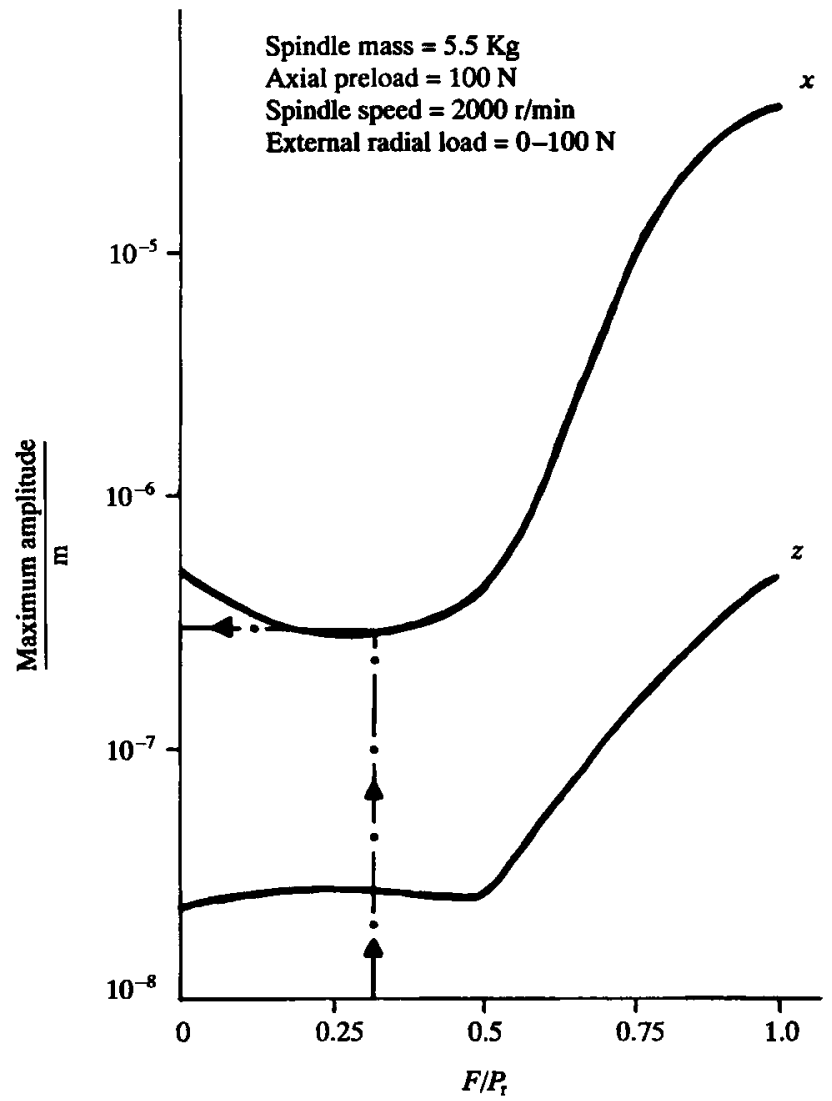

Fig. 6 The effect of the ratio $F / P_{\mathrm{r}}$ [taken from reference (4)]

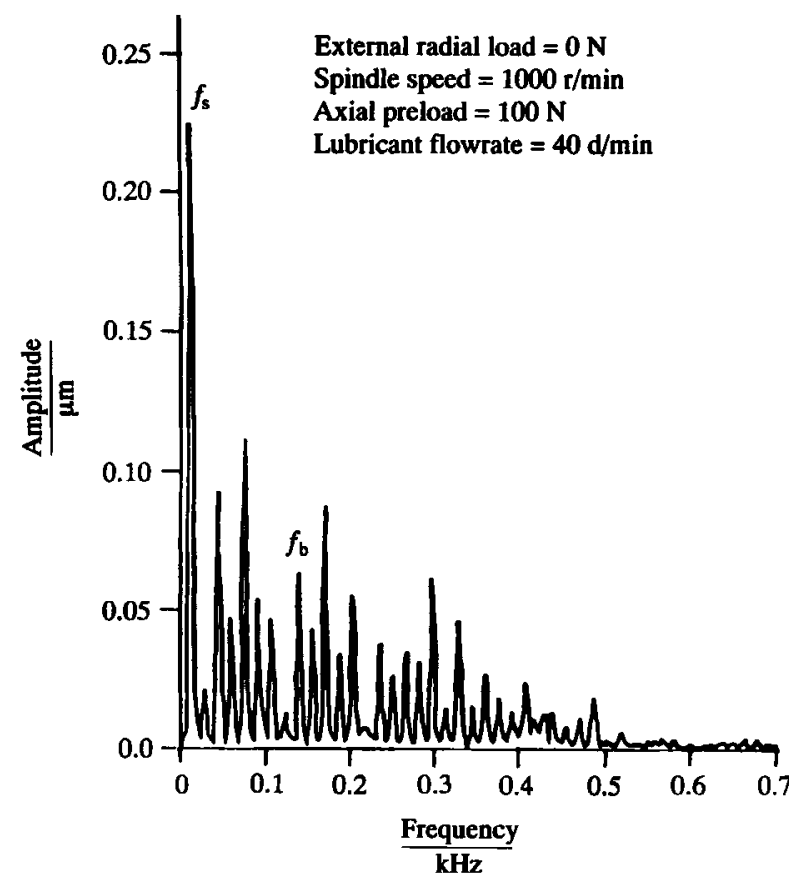

(a)

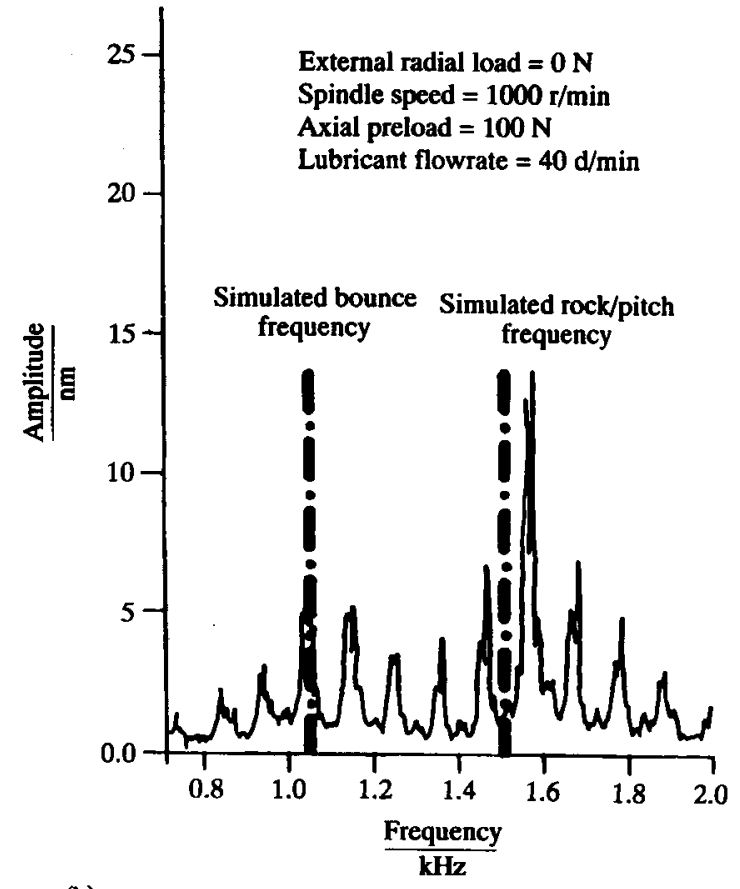

(b)

Fig. 7 Experimental frequency spectra at a spindle speed of $1000 \mathrm{r} / \mathrm{min}$ 
between the simulated and the monitored responses has been found both in terms of frequency as well as their corresponding amplitude of vibrations.

\section{ACKNOWLEDGEMENTS}

The authors would like to acknowledge the support extended to this project by RHP Bearing Research Centre. In particular the advice given by Drs S. Lacey and F. P. Wardle is greatly appreciated.

\section{REFERENCES}

1 Lacey, S. J., Wardle, F. P. and Poon, S. Y. High speed bearings for CNC machine tool spindles. CME, December 1983.

2 Wardle, F. P., Lacey, S. J. and Poon, S. Y. Dynamic and static characteristics of a wide speed range machine tool spindle. Precision Engng, October 1983, 5(4).

3 Aini, R. Vibration monitoring and modelling of shaft/bearing assemblies under concentrated elastohydrodynamic condition. PhD thesis, Kingston University, 1990.

4 Aini, R., Rahnejat, H. and Gohar, R. A five degree of freedom analysis of vibration in precision spindle. Int. J. Mach. Tools Manufact., 1990, 30(1), 1-18.

5 Aini, R. and Gohar, R. Vibration modelling of precision spindles supported by lubricated angular-contact-ball bearings. Trans. ASME, J. Lubric. Technol., December 1993 (submitted).

6 Rahnejat, H. and Gohar, R. Vibration of radial ball bearings. Proc. Instn Mech. Engrs, Part C, 1985, 199(C3), 181-193.

7 Harting, H. Demodulated resonance analysis-a powerful new incipient failure detection technique. Twenty-third International Instrument Symposium, Las Vegas, Nevada, 15 May 1977.

8 Wardle, F. P. and Poon, S. Y. Rolling bearing noise-cause and cure. $C M E$, July-August 1983.

9 Wardle, F. P. Vibration forces produced by waviness of the rolling surfaces of thrust loaded ball bearings. Part 1: theory. Proc. Instn Mech. Engrs, Part C, 1988, 202(C5), 305-312.

10 Wardle, F. P. Vibration forces produced by waviness of the rolling surfaces of thrust loaded ball bearings. Part 2: experimental validation. Proc. Instn Mech. Engrs, Part C, 1988, 202(C5), 313-319.

11 Meyer, L. D., Ahlgren, F. F. and Weichbrodt, B. An analytic model for ball bearing vibration to predict vibration response to distributed defects. Trans. ASME, J. Mech. Des., April 1980, 102

12 Hahn, R. S. Vibration of flexible precision grinding spindles. Trans. ASME, 1958, 80, 97.

\section{APPENDIX}

Referring to Fig. 1a, and considering $K_{1}$ and $K_{2}$ as the effective stiffnesses of the front and rear bearings, a simple two degree of freedom model yields the following equations of motion:

$$
\begin{aligned}
& m \frac{\mathrm{d}^{2} x}{\mathrm{~d} t^{2}}=-\left(K_{1}+K_{2}\right) x+\left(K_{1} b-K_{2} c\right) \theta \\
& I \frac{\mathrm{d}^{2} \theta}{\mathrm{d} t^{2}}=\left(K_{1} b-K_{2} c\right) x-\left(K_{1} b^{2}+K_{2} c^{2}\right) \theta
\end{aligned}
$$

Assuming a harmonic response of the form $x=A \cos \omega t$ and $\theta=\varphi \cos \omega t$, the governing equations above simplify to

$$
\begin{aligned}
& \left\{\left(K_{1}+K_{2}\right)-m \omega^{2}\right\} A=\left(K_{1} b-K_{2} c\right) \varphi \\
& \left\{\left(K_{1} b^{2}+K_{2} c^{2}\right)-I \omega^{2}\right\} \varphi=\left(K_{1} b-K_{2} c\right) A
\end{aligned}
$$

The amplitude ratio $A / \varphi$ can be obtained from both equations (3) and (4). Equating the two equations provides an expression of the form

$$
\psi \omega^{4}-\xi \omega^{2}+\gamma=0
$$

where

$$
\begin{aligned}
& \psi=m I \\
& \xi=\left(K_{1}+K_{2}\right) I+\left(K_{1} b^{2}+K_{2} c^{2}\right) m \\
& \gamma=\left(K_{1}+K_{2}\right)\left(K_{1} b^{2}+K_{2} c^{2}\right)-\left(K_{1} b-K_{2} c\right)^{2}
\end{aligned}
$$

The following data are used by letting $K_{1}=K_{2}=K$ :

$$
\begin{aligned}
m & =5.5 \mathrm{~kg} \\
I & =0.05177 \mathrm{~kg} \mathrm{~m}^{2} \\
b & =0.0875 \mathrm{~m} \\
c & =0.174 \mathrm{~m} \\
K & =108 \mathrm{MN} / \mathrm{m} \text { (equivalent linear bearing stiffness) }
\end{aligned}
$$

Therefore solving equation (5), the values of $\omega$ obtained with this simple analytical model are

$$
\begin{aligned}
f_{1}=\omega_{1} / 2 \pi= & 910 \mathrm{~Hz}, \\
& \text { corresponding to the bounce mode } \\
f_{2}=\omega_{2} / 2 \pi= & 1470 \mathrm{~Hz}, \\
& \text { corresponding to the rock/pitch mode }
\end{aligned}
$$

It can be observed that these values agree quite closely with the experimentally obtained bounce and rock frequencies. 